\title{
Analysis of the Suppression Device as Vortex Induced Vibration (VIV) Reducer on Free Span using Finite Element Method
}

\author{
Dwi Priyanta ${ }^{1}$, Anang Abdullah ${ }^{2}$
}

\begin{abstract}
The uneven topography surface of the sea floor resulting the pipe undergoes free span. The free span is a condition endured by the pipe where the pipe position has distance or gap with the seabed supported by two pivot. The free span is at risk of experiencing a vibration caused by the presence of dynamic load that is current and the wave. The vibration that occurs is the impact of the presence of the phenomenon of Vortex Induced Vibration (VIV). The Phenomenon Of VIV occur on a cylindrical component caused by ocean currents, causing the occurrence of vibration by the movement of fluid on the pipe so that it raises the vortex at the rear of the direction of oncoming flow. One way to dampen or reduce the impact of VIV is by adding suppresion device. VIV suppression device is a tool that is installed on the pipeline on offshore piping installationcthat serves to dampen or reduce the impact of VIV. One of the simulations used to know the characteristics of a fluid is to use (CFD) Computational Fluid Dynamic. With the addition of suppression device can add the rest of the operating time on a free span of affected VIV, on the condition of free span critical exposed VIV (Vortex Induced Vibration value) has a life time on plain pipe 44.21 years, on pipe with 53.09 years and Fairing on the pipe with the Helical strike 52.95 year.
\end{abstract}

Keywords - pipelines, free span, VIV, suppression device,life time.

\section{INTRODUCTION}

$\mathrm{S}_{\mathrm{u}}$ ubsea pipeline is a transportation infrastructure of oil and gas as an alternative for ship tanker. The uneven topography surface of the sea floor resulting the pipe undergoes free span. Figure 1 illustrates the phenomenon of free span [1].

The free span is a condition endured by the pipe where the pipe position has distance or gap with the seabed supported by two pivot [2]. Moreover the free span is also at risk of experiencing a vibration caused by the presence of dynamic load that is current and the wave. The vibration that occurs is the impact of the the use the EJGP to transmit the results of their gas, is KEI (Kangean Energi Indonesia) in Pagerungan and Terang Sirasun Batur, PGN (Santos) on the Maleo MOPU PJU (Petrogas Jatim Utama). Kangean Energi Indonesia send 15 MMscfd from Pagerungan and 250 MMscfd from Terang Sirasun Batur and PGN (Santos) sent 85 MMscfd of gas from Maleo field. Every day approximately 350 MMscfd on distributed using the EJGP [3-4].

Kangen Energy Indonesia uses the EJGP to send gas to the Petro Kimia Gresik and Java Bali Poitrplant (PJB) in the area of Gresik. PGN (Santos) send gas to the customer in Porong Sidoarjo [5].

From the underwater data survey conducted on Maleo Field line to the EJGP $7353 \mathrm{~km}$ along on December 25, 2012 up to January 21, 2013 obtained data free span as many as 179 with different characteristics [5].

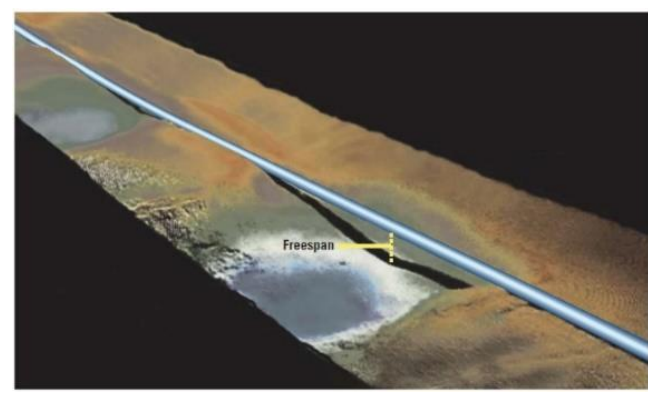

Figure. 1. Free Span Ilustration

existence of the phenomenon of Vortex Induced Vibration (VIV) [3].

One of the pipeline in Indonesia is the EJGP (East Java Gas Pipeline) which starts from Pulai Pagerungan Great to Gresik 350 Kilometers along the PKG with diameter of 28 inches. (Figure 2). There are three Gas producers

Dwi Priyanta is with Department of Marine Engineering, Institut Teknologi Sepuluh Nopember, Surabaya 60111, Indonesia. E-mail: priyanta@its.ac.id

Anang Abdullah is with Department of Marine Engineering, Institut Teknologi Sepuluh Nopember, Surabaya 60111, Indonesia. 


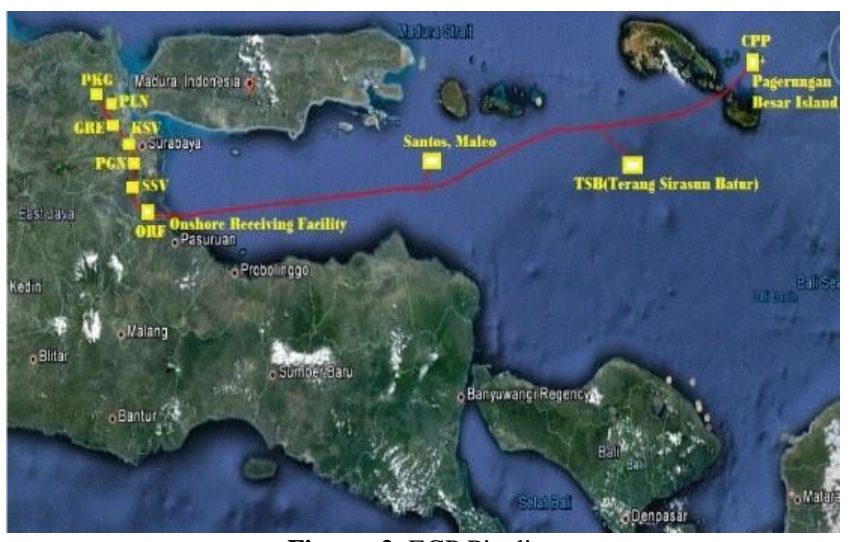

Figure. 2. EGP Pipeline
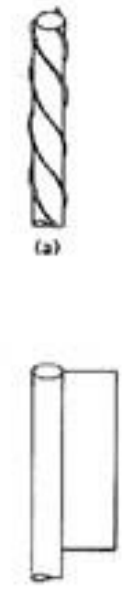

(e)
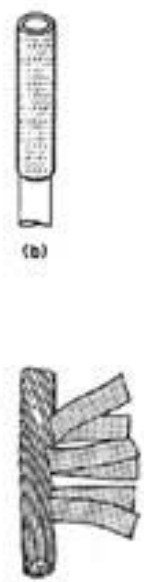

(1)
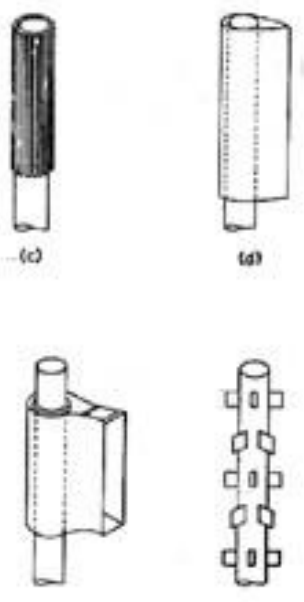

(乌)
(4) (b)

Figure. 3. Various kinds of suppresion device VIV

VIV phenomenon occurs on the cylindrical component caused by the ocean currents. Ocean currents has been caused the occurrence of vibration on structures caused by the movement of the fluid on the pipe raises the vortex at the rear of the direction of the oncoming flow. One way to dampen or reduce the impact of VIV is to add suppresion device. Suppression device (Figure 3) VIV is a tool mounted on a pipe on the offshore pipeline installation serve to dampen or reduce the impact of VIV. There are several types of suppresion device such as shows in figure 3 description of various kinds of suppression device viv as follow: (a) helical stake, (b) shroud, (c) axial plates, (d) streamline fairing, (e) splitter, (f) ribbon cable, (g) pivoted guiding vane, (h) spoiler plates [6].

\section{METHOD}

Generally the stages of workmanship is divided into three. The first phase of screening is conducted free span in accordance with existing criteria in DNV RP F-105 Free Spanning Pipelines that is static screening and dynamic screening, hereafter the second step in the form of simulation and modeling of critical free span and final step is calculates the life time of critical free span condition without suppression device, and with the addition of suppression, then compared to what has most great life time.

The first step in this thesis work is conduct studies of the literature books and various journal for knowing the types of Suppression device. Come by two types of Suppression device i.e. Helical strike and Fairing to compared in reduce the impact of VIV. Then look for size/dimensions of these two types of suppression device.

Free span data along the lines of Maleo field to the EJGP screening is done in the form of static screening (L/D < 30) and dynamic screening (allowable length due to cross flow and inline) in accordance with the existing criteria in DNV RP F-105 [7-8].

Results of screening free span is critical free span the has been be made the object of simulation in compare the suppression device. The second step namely fatgue life calculations. Some data such as pressure and velocity in the happening VIV process simulation of Finite Element Method (FEM) using software Ansys Fluent. Next look for the value of Stress range on critical free span from $\mathrm{SN}$ curve. From a various of SN Curve, used the SN curve which has a characteristic such as owned by pipe from the Maleo field to the EJGP. After getting the value of stress range then it has been obtained a value of Dfat. The Value Of $D$ fat has been be used to calculate the value of the remaining operating time on the third stage. The last step that is doing the calculation of lifetime. From the results of the calculation of life time third pipe, next comparing which have the longest life time. From the results of the comparisons has been get the kind of suppression device that is best in reducing the impact of VIV.

\section{RESULTS AND DISCUSSION}

\section{A. Free Span Modelling And Simulation}

For modeling and simulation are not performed on all free span but only on critical free span. Before 
TABLE 1.

SIMULATION RESULT

\begin{tabular}{cccc}
\hline & Plain Pipe & Fairing & Helical \\
\hline $\mathrm{V}_{\mathrm{R}}(\mathrm{m} / \mathrm{s})$ & 0,67 & 0,36 & 0,34 \\
\hline
\end{tabular}

determining the critical free span do screening geometru L/D $<30$ and a maximum length of on the Inline- Cross flow conditions, obtained critical free span with the following criteria:

a. Free span did not qualify a screening level 1 (L/D < 30)

b. Do not qualify for screening level 2 (maximum length on the In-line condition and the condition of cross flow)

c. Has the longest free span length.

d. from the above criteria selected free span on Kilometres Post (KP) 3118 up to 3147 with the depth of 60 meters and a length of free span $29 \mathrm{~m}$.

From the above criteria selected free span on Kilometre Post (KP) 3118 up to 3147 to a depth of 60 metres and a length of free span $29 \mathrm{~m}$. Selected free span has been be simulated three times: first free span with conditions without the suppression device, second free span with the addition of a helical strike, third free span with the addition of the fairing.

\section{B. Simulation And Validation Result}

The data obtained from the simulation results that speed vortex area needs to be validated whether the simulation is quite accurate. Way to validate that is to compare results simulated with the calculation mathematically. In this case referenced in validating the results of the simulation value velocity vortex region or Reduction called velocity (VR ) On plain pipe, $=\mathrm{V} / \mathrm{Fn}$ $\mathrm{x} D$ is only valid on the condition of the pipe plain. The results obtained from the calculation of the value of $\mathrm{V} \mathrm{R}$ on critical free span is $0.72 \mathrm{~m} / \mathrm{s}$ while the value of $\mathrm{V}$ of the simulation results is $0.67 \mathrm{~m} / \mathrm{s}$. In result the simulation has been be performed on the pipe by helical and fairing with the same boundary setting condition as was done on the plain pipeline. For the results of the third simulation is as following in Table 1.

\section{Stress Range Calculation}

Stress range that what is meant is caused by vibration or Vibration can be called Stress Range. The value of the stress of this range has been be plotted to the curve of SN to get values of $\mathrm{N}$ (Number of cycle to failure)/number of cycles make pipe fails at a certain range of stress values (Figure 4). To get the value of the stress range used the equation as follows:

Where :
A IL $=$ stress amplitude
$=\mathrm{C} 4 \times(1+\mathrm{CSF}) \times(\mathrm{D} \times(\mathrm{Ds}-\mathrm{t}) \times \mathrm{E}) / \mathrm{L}$
C4 $=4,93($ DNV RPF 105)
$\mathrm{CSF}=1$ (concrete stiffnes factor, DNV 3.3.8)
D = outside diameter
Ds = pipe diameter without coating
$\mathrm{t} \quad=$ pipe thickness
$\mathrm{E} \quad=$ itng Modulus
$\mathrm{L} \quad=$ free span lenght
AY/D = amplitude Response
$\mathrm{S} \quad=$ Safety factor
So,
A IL $=352,44 \mathrm{Mpa}$

For the plain pipe :

SIL $=2 \times 352,44 \mathrm{MPa} \times 0,11 \times 1,3=100,798 \mathrm{MPa}$

For the another value of SIL can be seen in table 2 . Each of these values has been be plotted on a stress range

SN curve to get the value of $\mathrm{N}$.

\section{SN Curve Recitation}

For values of $\mathrm{N}$ obtained from the SN Curve recitation which is a function of the Stress range. The value of stress range which have found pulled horizontal line to the right to intersect with the lines curve B2, from the

TABLE 2.

STRESS RANGE CALCUlation RESUlt

\begin{tabular}{ccc}
\hline & \multicolumn{3}{c}{ STRESS RANGE CALCULATION RESULT } \\
\hline & $\mathrm{S}_{\mathrm{IL}}=2 \mathrm{X} \mathrm{A}_{\mathrm{IL}}\left(\mathrm{A}_{\mathrm{Y}} / \mathrm{D}\right) \mathrm{X} \mathrm{S}$ & \\
\hline & $\mathrm{A}_{\mathrm{Y}} / \mathrm{D}$ & $\mathrm{S}_{\mathrm{IL}}(\mathrm{MPa})$ \\
\hline Plain Pipe & 0,11 & 100,798 \\
Fairing & 0,08 & 73,308 \\
Helical & 0,07 & 64,144 \\
\hline
\end{tabular}

TABLE 3.

N CALCULATION RESULT

\begin{tabular}{ccc}
\hline & & \\
& $\mathrm{S}_{\text {IL }}(\mathrm{MPa})$ & $\mathrm{N}$ \\
\hline Plain Pipe & 100,798 & 6.100 .000 \\
Fairing & 73,308 & 36.000 .000 \\
Helical & 64,144 & 70.000 .000 \\
\hline
\end{tabular}




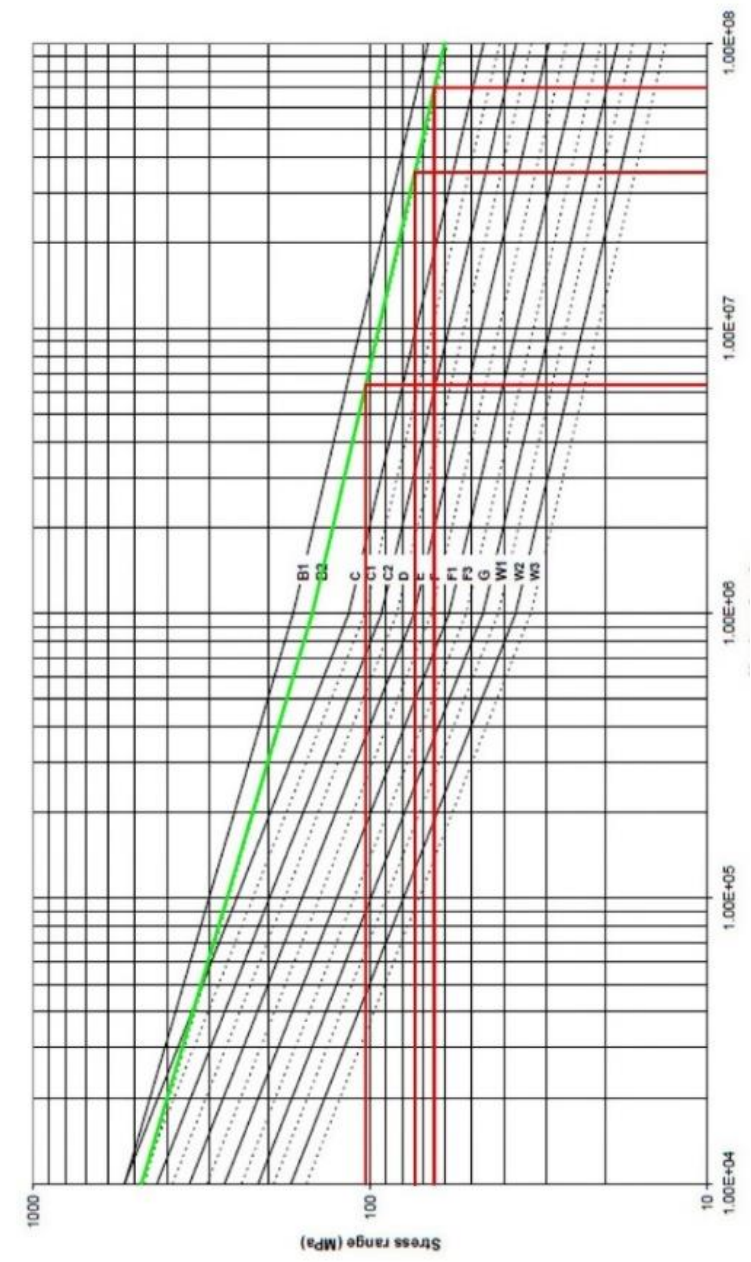

Figure. 4. SN Curve recitation

intersection of a vertical line is pulled down to get the value of $\mathrm{N}$. Following is the results of $\mathrm{SN}$ curve recitation $\mathrm{N}$ calculation result shows in table 3 .

The value of ni and $\mathrm{N}$ has been be used to calculate the value of Dfat (Damage Accumulation).

\section{E. Fatigue Life Calculation}

Pipes that get continuous load within a certain period has been experience tiredness or fatigue. To accomplish this, it can be done with reference to the following equation:

Dfat $\quad=\mathrm{Sni} / \mathrm{Ni}$

So to pipe a plain Dfat value is as the following:

Dfat $\quad=6.898 .000 / 6.600 .000$

$$
=1.05
$$

For the value of Dfat on fairing pipe and helical pipe can be seen in the following table 4 .

\section{F. Compare The Life Time}

Because it has been be compared to the value of Life

TABLE 4.

FATIGUE DAMAGE CALCULATION RESULT

\begin{tabular}{cccc}
\hline & $\mathrm{Ni}$ & $\mathrm{ni}$ & \\
& \multicolumn{1}{c}{ FATIGUE DAMAGE CALCULATION RESULT } \\
\hline Plain Pipe & 6.100 .000 & 6.898 .000 & 1,13 \\
Fairing & 36.000 .000 & 33.904 .509 & 0,942 \\
Helical & 70.000 .000 & 66.102 .395 & 0,944 \\
\hline
\end{tabular}

time on plain pipe, a pipe with a fairing and pipes with helical fit with the objectives of this thesis. For can calculate the life time equations the following:

$\mathrm{TLife}=\mathrm{T} \exp /$ Dfat $\mathrm{x} \eta$

Where :

Texp = estimated life time at design $=$ for this case is assumed to be 50 years.

Dfat = Damage accumulation

$\eta \quad=$ safety factor for fatigue (normally $=1$ )

So the value of the Life time for plain pipe is:

$$
\begin{aligned}
\text { Tlife } & =50 \text { years } / 1,131 \times 1 \\
& =44,21 \text { years }
\end{aligned}
$$

Results for life time on a fairing pipe and Helical pipe can be seen in the following table 5 . 
TABLE 5.

LiFETIME CALCULATION RESUlT

\begin{tabular}{ccc}
\hline & Dfat & Life Time (Years) \\
\hline Plain Pipe & 1,13 & 44,21 \\
Fairing & 0,942 & 53,09 \\
Helical & 0,944 & 52,95 \\
\hline
\end{tabular}

\section{CONCLUSION}

Based on the analysis, it brings the conclusion is as follows:

1. After the simulation obtained the value of VR (speed in the vortex) on the plain of pipe $0.72 \mathrm{~m} / \mathrm{s}$, pipe with Fairing $0.36 \mathrm{~m} / \mathrm{s}$ and pipe with Helical strike $0.34 \mathrm{~m} / \mathrm{s}$.

2. The calculation of Vibration Stress range (S) which is a function of VR, known the greater value of VR the greater value of vibration stress range has been be, for plain pipe $100.798 \mathrm{Mpa}$, pipe with Fairing 73.308 Mpa and pipes with Helical strike 64.144 $\mathrm{MPa}$. With its greater value of stress range received by the pipe then the value $\mathrm{N}$ (the number of the cycle to be failing) getting smaller which means the pipe also has a small ni stress cycle.

3. By comparing the value of $\mathrm{Ni}$ and ni then obtained the value of fatigue damage (Dfat). So with assume that the pipe is designed to operate for 50 years, on the condition of the critical free span exposed VIV (Vortex Induced Vibration) the life time value on plain pipe 44.21 years, at and Fairing pipe with 53.09 years and on the pipe with the Helical 52.95 strike year.

4. With the addition of suppression device it can Add the remaining operating time at free span which affected by VIV, on free span KP 3.118 until 3.147 obtained addition of the remaining acquired operating time using suppression device type of fairing 8.88 years while on strike of Helical type 8.74 years.

\section{REFERENCES}

[1] Alkazraji, Duraid, "A Quick Guide Pipeline Engineering," Woodhead Publishing Limited, England. 2008.

[2] Dalton, Charles, "Fundamentals of Vortex Induced Vibration," University of Houston, England. 2013.

[3] Bai, Yong, "Pipelines and Risers," Elsevier, USA, 2001

[4] Guo, Boyun, “Offshore Pipeline,” Elsevier Inc. USA, 2005.

[5] Don W. Allen, SGS, "Fairing versus Helical Strakes for Suppression of Vortex-Induced Vibration:Installation, Maintanance and Economic Considerations," Offshore Technology Conference, Houston Texas USA, 2008

[6] Don W. Allen, "Fairing versus Helical Strakesfor Suppression of Vortex-Induced Vibration:Technical Comparisons," Offshore TechnologyConference, Houston Texas USA, 2008

[7] DNV RP C203, "Fatigue Design of Offshore Steel Structure," 2011

[8] DNV RP F105, "Free Spanning Pipelines," 2006. 